\title{
Chapter 7 \\ Remote Sensing-Based Monitoring of Potential Climate-Induced Impacts on Habitats
}

\author{
Michael Förster, Marc Zebisch, Iris Wagner-Lücker, Tobias Schmidt, \\ Kathrin Renner, and Marco Neubert
}

\subsection{Introduction}

Climate change is likely to be a strong driver of changes in habitat conditions and, subsequently, species composition. Sensitive and accurate monitoring techniques are required to reveal changes in protected areas and habitats. Remote sensing bears the potential to fulfil these requirements because it provides a broad view of landscapes and offers the opportunity to acquire data in a systematic, repeatable, and spatially explicit manner. It is an important tool for monitoring and managing habitats and protected areas as it allows the acquisition of data in remote and inaccessible areas. This is important since traditional field-based biodiversity assessment methods (although far more detailed and often more accurate) are sometimes subjective and usually spatially restrained due to constraints in time, finance, or habitat accessibility. Remote sensing can provide indicators for different spatial and

\footnotetext{
M. Förster $(\bowtie) \bullet T$. Schmidt

Geoinformation in Environmental Planning Lab, Department of Landscape Architecture and Environmental Planning, Technical University of Berlin, Str. d. 17. Juni 145, 10623 Berlin, Germany

e-mail: michael.foerster@tu-berlin.de

M. Zebisch • K. Renner

Institute for Applied Remote Sensing, EURAC Research, Viale Druso 1, 39100 Bolzano, Italy

I. Wagner-Lücker

Department of Conservation Biology, Vegetation- and Landscape Ecology,

University of Vienna, Rennweg 14, 1030 Vienna, Austria

Department of Limnology, University of Vienna, Althanstrasse 14, 1090 Vienna, Austria e-mail: iris.wagner@univie.ac.at

M. Neubert

Leibniz Institute of Ecological Urban and Regional Development,

Weberplatz 1, 01217 Dresden, Germany

e-mail: m.neubert@ioer.de
} 
temporal scales ranging from the individual habitat level to entire landscapes and involving varying temporal revisit frequencies up to daily observations.

Habitat mapping is developing at a fast rate within the two basic approaches of field mapping and remote sensing. The latest technologies are quickly incorporated into habitat monitoring (Lengyel et al. 2008; Turner et al. 2003). Field mapping, for example, is facilitated by the use of object-oriented methods or wireless sensor systems (e.g. Polastre et al. 2004; Bock et al. 2005). Additionally, advances in remote sensing methods have resulted in the widespread production and use of spatial information on biodiversity (Duro et al. 2007; Papastergiadou et al. 2007; Förster et al. 2008). In fact, earth observation data is becoming more and more accepted as an appropriate data source to supplement, and in some cases even replace, field-based surveys in biodiversity science and conservation, as well as in ecology. Objectivity and transparency in the process of integrity assessments of Natura 2000 sites can be supported by quantitative methods, if applied cautiously (Lang and Langanke 2005). However, it should be kept in mind that there are various sources of uncertainty in remote sensing-based monitoring of vegetation (Rocchini et al. 2013).

Despite all the advantages mentioned above, the monitoring of habitats using fieldbased and remote sensing approaches has a very short history. Landsat-4, the first non-military optical sensor with the potential to monitor habitats at a suitable spatial resolution, was initiated only in 1982 . Even within this time period the story of image acquisition and interpretation is not free of interruptions due to sensor faults and a lack of financial support for continuity missions (Wulder et al. 2011). Recently, the sensor series RapidEye and the planned mission Sentinel-2, which employ a constellation of multiple identical satellites, have been supplying data with a higher temporal frequency (Berger et al. 2012). However, this time-span is still not long enough to allow reliable statements about modifications of habitats dependent on climate change.

This study focuses on the potential of remote sensing to detect indicators related to climate change in three focus areas. The case studies presented use the Natura 2000 habitat nomenclature and descriptions of the conservation status of the protected habitats as a basis for their evaluation. For all studies within this chapter, RapidEye products acquired between 2009 and 2011 were used as basic imagery for the subsequent investigations due to their frequent availability and suitable spectral as well as spatial resolution. The acquired images were always used in combination for a single mapping step. The necessary time-frame for monitoring with repeated image acquisition (e.g. a 6-year cycle as proposed in the EC Habitats Directive) was not available within the HABIT-CHANGE project.

Within the general framework described (Natura 2000-related indicators, RapidEye data from 2009 to 2011), methods for various habitats in three different biogeographic regions (Continental, Alpine, Pannonian) were applied. The techniques, which are described in the following subchapters, are intended to demonstrate their potential for indicating likely climate change impacts. In the Vessertal, a forested area in Germany, the immigration of beech into a spruce dominated region a potential effect of climate change - was investigated (Sect. 7.2). In the Lake Neusiedl area in Austria potential climate-induced changes in Pannonic inland marshes are shown (Sect. 7.3). In Rieserferner Ahrn, an Alpine region in Italy, the potential of detecting shrub encroachment - an indicator for climate-related change to the treeline - was explored (Sect. 7.4). 


\subsection{Case Study Forest Habitats: Vessertal, Germany}

A detailed description of the study area Vessertal is found in Sect. 16.2. In Chap. 16, climate change related sensitivity of forests in general and the Vessertal specifically is also described. This section, therefore, provides only a summary of the main facts of the region. With $88 \%$ forest cover, the Biosphere Reserve Vessertal can be characterised as a landscape almost completely covered by woodland. The main tree types are spruce and beech. In terms of protected habitats Luzulo-Fagetum beech forests (habitat code 9110) and Asperulo-Fagetum beech forests (habitat code 9130) are of major importance (see Table 16.1).

As already mentioned above, only a long-term study can provide facts about the immigration of beeches into spruce dominated areas as may be occurring in the Vessertal region. However, the multi-temporal based short-term habitat quality indicator presented here can be used to detect the actual status of tree species compositions within the protected areas. Using this approach a detailed and accurate differentiation of tree species can be obtained. Knowledge about the current status of the tree population is important information for decision makers, helping them plan further management measures for conservation of the Natura 2000 habitat types.

\subsubsection{Data and Methods}

For this study a multi-temporal series of RapidEye data (Level 3A) for the study area Biosphere Reserve Vessertal (Table 7.1) was obtained in 2011. Four images with the acquisition dates 24-04-2011, 08-05-2011, 26-08-2011, and 23-10-2011 were available. The RapidEye mission represents a constellation of five satellites and provides high spatial resolution multi-temporal imagery. Five optical bands cover a range of $400-850 \mathrm{~nm}$, whereby the first three bands represent the visible spectral range $(400-685 \mathrm{~nm})$. Band 4 covers the red-edge wavelength $(690-730 \mathrm{~nm})$, which is very sensitive for vegetation chlorophyll, and band 5 covers the near-infrared $(760-850 \mathrm{~nm})$. The spatial resolution is $6.5 \mathrm{~m}$ for level $1 \mathrm{~B}$ data and resampled to $5 \mathrm{~m}$ for orthorectified level 3A data (Schuster et al. 2012).

Table 7.1 Percentage of the share of natural tree types as an example indicator for the determination of conservation status for Luzulo Fagetum beech forests and Asperulo Fagetum beech forests $(\geq 90 \%$ beech $=$ favourable; between 80 and $90 \%$ beech $=$ unfavourable - inadequate; below $80 \%$ beech $=$ unfavourable - bad). The areas reported as Asperulo Fagetum beech forests show a higher share of favourable conservation status than Luzulo Fagetum beech forests

\begin{tabular}{lll}
\hline Conservation status & Luzulo Fagetum $(9110)$ & Asperulo Fagetum $(9130)$ \\
\hline Favourable & $14.19 \%$ & $57.68 \%$ \\
Unfavourable - inadequate & $30.61 \%$ & $37.73 \%$ \\
Unfavourable - bad & $55.19 \%$ & $4.58 \%$ \\
\hline
\end{tabular}




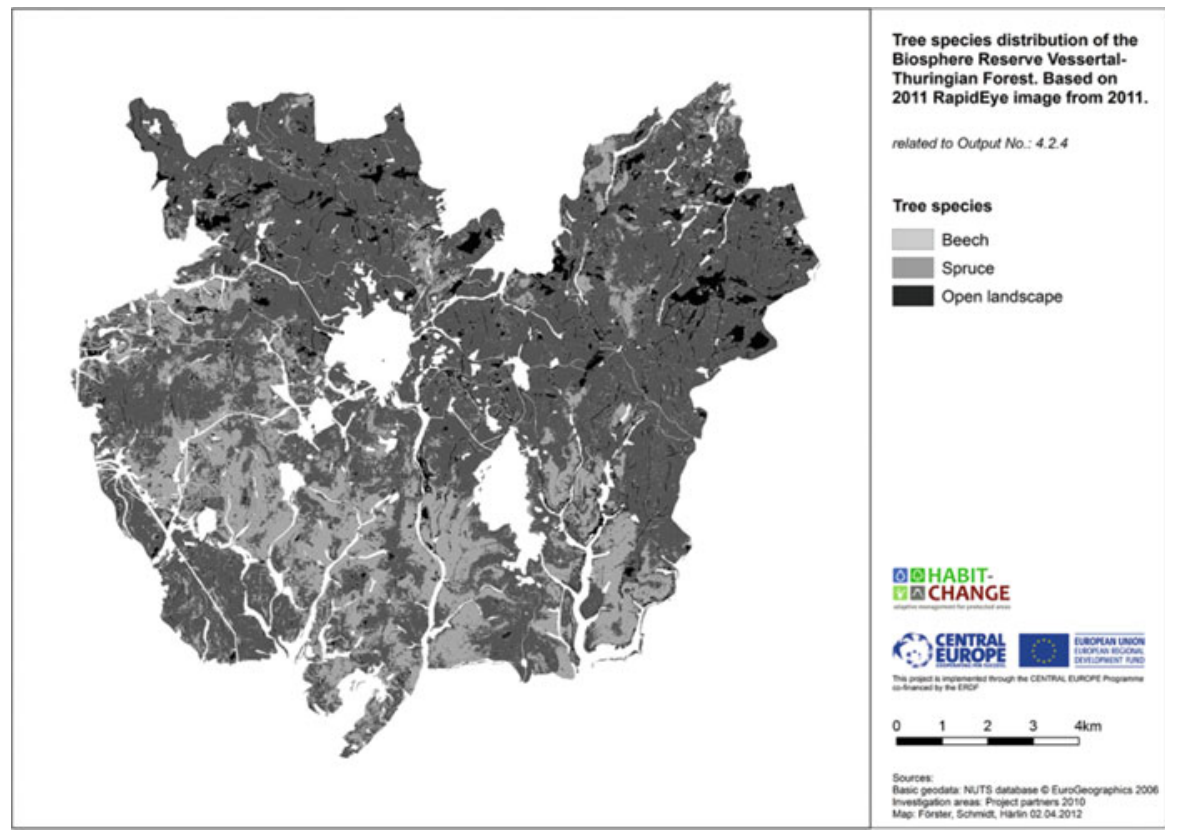

Fig. 7.1 Tree species distribution of the Biosphere Reserve Vessertal based on RapidEye satellite images from 2011

The pre-processing of the images included geometric correction (image-to-image) and radiometric normalisation to a cloud-free reference image in the middle of the vegetation period with a high radiometric quality (RapidEye image from 26-08-2011) to adjust the spectral variability. The IR-MAD algorithm implemented in ENVI/IDL was used for the radiometric normalisation. This algorithm automatically detects no-change pixels based on a no-change probability threshold and performs a relative radiometric normalisation of the images (Canty and Nielsen 2008).

Since the spatial accuracy of additionally available forest inventory data was insufficient to generate training samples for a supervised tree species classification, an unsupervised Isodata classification was performed in order to allocate spectral homogeneous clusters. These clusters were visually interpreted using aerial photographs and attributed to the classes beech, spruce, or open landscape. Subsequently, for each class, 1,000 random sample points were generated based on these spectral homogeneous areas. From these extracted sample points, a supervised classification, based on multi-temporal data using the Support Vector Machine (SVM) algorithm (Karatzoglou et al. 2005), was performed to generate a thematic tree species map (Fig. 7.1). For this process the samples were portioned into $70 \%$ for the training of the SVM and $30 \%$ for the validation. Thereafter, the tree species map was intersected with each of the existing Natura 2000 habitat type boundaries, which were available as a field-based mapping GIS-layer for reporting purposes from the Vessertal Biosphere Reserve. The tree species compositions (beech/spruce) per polygon were computed based on this independent data source. 


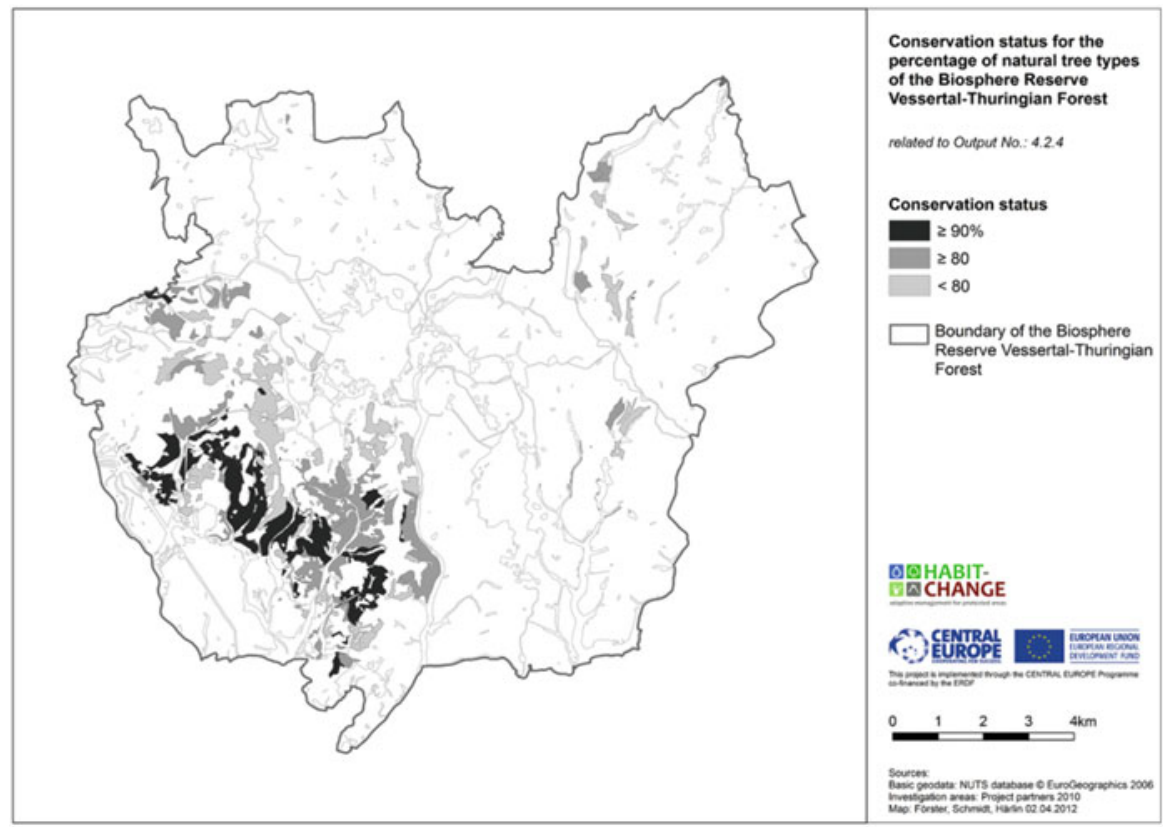

Fig. 7.2 Map of the percentage of natural tree types as an example indicator for the determination of conservation status $(\geq 90 \%$ beech $=$ favourable; $\geq 80 \%=$ between 80 and $90 \%$ beech $=$ unfavourable - inadequate; below $80 \%$ beech = unfavourable - bad)

This approach enables detailed monitoring of habitat quality related to the tree species compositions. In terms of Natura 2000 in Germany, objective mapping guidelines with defined rules are available to determine the conservation status of a forest habitat (Burkhardt et al. 2004). These parameters define the status of a specific Natura 2000 site (e.g. favourable, unfavourable - inadequate, or unfavourable - bad). One indicator, suitable for remote sensing applications, is the percentage of natural forest types in terms of the abundance of specific species (Förster and Kleinschmit 2008). For this indicator, the tree species composition per polygon was calculated.

\subsubsection{Results}

The classification of the RapidEye images provides a detailed distribution of the tree species in the Biosphere Reserve Vessertal (Fig. 7.1). Spruce covers approximately $62 \%$, beech $30 \%$, and open landscape $8 \%$ of the study site. The overall accuracy of the result is $88 \%$, so it was accepted as accurate enough to derive the indicator "percentage of natural forest types" for the Natura 2000 conservation status. The results of the percentage of tree species within the boundaries of the field-based delineated habitat types are depicted in Fig. 7.2. 
In an exemplary evaluation of the conservation status for Luzulo Fagetum beech forests and Asperulo Fagetum beech forests, relying just on this single indicator, it can be shown that the conservation status of Asperulo Fagetum is more often favourable than for Luzulo Fagetum (Table 7.1), which corresponds with the findings of the field-based mapping presented in Chap. 16.

\subsubsection{Conclusions}

The results of the case study Vessertal illustrate the successful evaluation of an indicator of the conservation status of continental forest habitats (percentage of natural tree types). However, not all indicators defined for the conservation status of woodlands in Germany are detectable with RapidEye imagery. The differentiation of habitat types often relies on the understorey vegetation, which is not detectable using earth observation techniques. Within forest habitats a combination with LiDAR (Light Detection and Ranging) techniques has proven to be relatively helpful (Vehmas et al. 2009). However, the exploration of a set of indicators detectable by remote sensing that may complement the field-based data-set remains under discussion. In terms of climate change, the indicator evaluated here, percentage of natural tree types, can be utilised to monitor the immigration of beech into a spruce dominated region of the Thuringian Forest.

\subsection{Case Study Wetland Habitats: Lake Neusiedl, Austria}

\subsubsection{Study Area}

The transboundary Lake Neusiedl/Fertő-Hangság National Park was founded in 1993. It is situated at the Austrian and Hungarian border (see Fig. 1.1). Lake Neusiedl itself is - in hydrological terms - a steppe lake, the westernmost of a series of steppe lakes extending throughout Eurasia. It is especially sensitive to climate variations due to its extreme shallowness and small catchment area. Historical records indicate that large variations of the lake area have occurred naturally. However, today a constant water level is maintained by water engineering measures. Considering future climate scenarios, the main risk for Lake Neusiedl is significant water losses that could enhance eutrophication and algal growth (Soja et al. 2013).

East of the lake approximately 80 shallow saline ponds can be found. Nowadays, this area is determined by the spread of reed stands, smaller ponds created by the interconnection of the former bay-type formations, and smaller bays. Furthermore, reed in general is the most characteristic habitat in the region, covering more than $70 \%$ of the protected area. Its structure ranges from very dense and impassable to 
sparse stands mixed with stretches of open water. In addition to reed, inland marshes (habitat code: $1530^{*}$ - the star indicates a priority habitat) and calcareous fens (habitat codes: $7210 \& 7230^{*}$ ) can be found in this region. In contrast to the larger patches of reed, these habitats are considered to be of European importance in terms of the EC Habitats Directive.

\subsubsection{Data and Methods}

For this case study two RapidEye images from 2009 (April and August, Level 3A), a Digital Elevation Model (DEM) to detect small altitude differences, and CORINE Land Cover data were used.

Within the European Union inland marshes are found solely in the region of Lake Neusiedl. They are greatly disturbed by increased nutrition input, changes in hydrology, regrowth of atypical plant types, and a decrease of land-use or degradation through intensive land-use. Some of these disturbances can be related to climate-induced impacts (e.g. change in moisture conditions). The Environmental Agency Austria uses an indicator-based approach to evaluate the quality of these habitats. The indicators employed are area, species composition, hydrology, completeness of typical habitat structures, and presence of disturbance indicator plant species. Here, a similar approach is used to develop potential habitat maps to support the monitoring process and consequently to detect areas not known to be covered by inland marshes. Because most of these indicators cannot be derived from satellite data, moisture and biomass were used for this investigation.

Moisture can be measured with the Normalised Difference Water Index (NDWI Eq. 7.1) adapted for multi-spectral sensors (Gao 1996). This index allows the detection of water bodies and wet surfaces by utilising the spectral reflectance of the visible green wavelength and the near infrared (NIR). The requirements of inland marshes regarding water availability vary significantly. The amplitude ranges from temporary very dry periods (for alkali steppe) to periodic flooding (for salt steppes or salt marshes). Therefore, the NDWI is used to detect areas with periodically changing moisture conditions and permanently flooded or dry areas.

$$
\mathrm{NDWI}=(\text { Green }-\mathrm{NIR}) /(\text { Green }+\mathrm{NIR})
$$

Biomass can be approximated with the Normalised Difference Vegetation Index (NDVI - Eq. 7.2: Tucker 1979). This index is the common vegetation index for the detection of active biomass in remote sensing applications. In this study, the NDVI is used for detecting species which indicate a disturbance of inland marshes. Especially relevant here is reed, which has considerably high biomass production and replaces the common vegetation composition of inland marshes.

$$
\mathrm{NDVI}=(\operatorname{Red}-\mathrm{NIR}) /(\operatorname{Red}+\mathrm{NIR})
$$




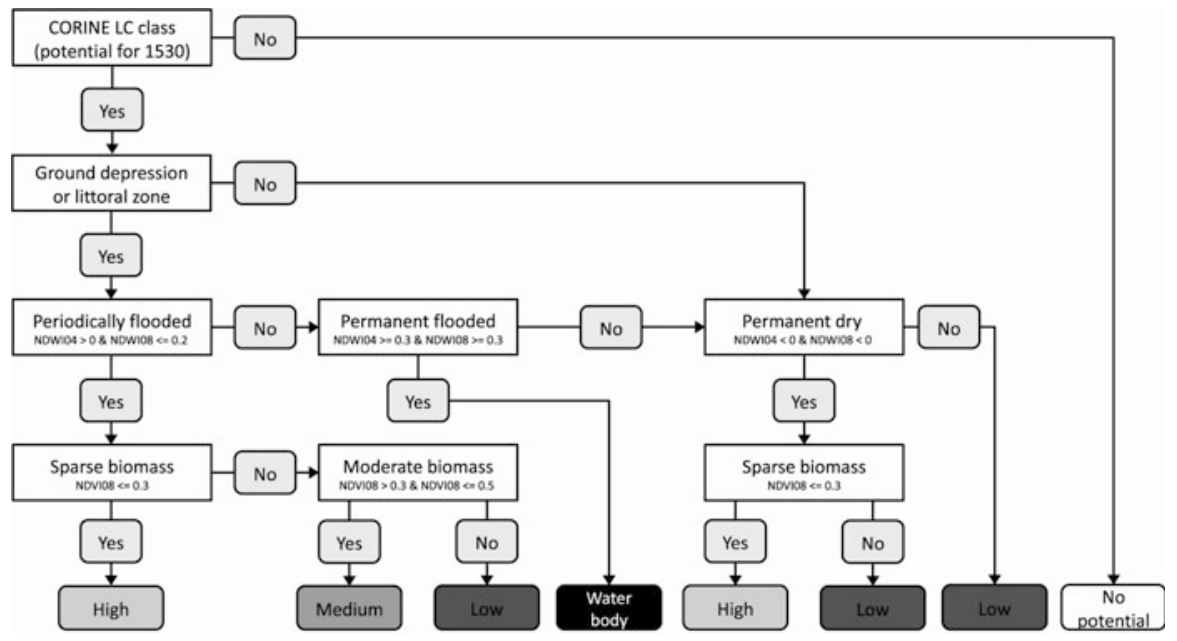

Fig. 7.3 Hierarchical classification approach for mapping of potential occurrence of inland marshes

Additionally, a DEM with a spatial resolution of $5 \mathrm{~m}$ and a ground depression detection map were used. Since especially salt steppes and salt marshes are closely related to the ground or sea water level, it can be assumed that ground depressions provide a high potential for this habitat type. The same applies to littoral zones beside the lake. However, littoral zones are not detected as ground depressions, since the entire littoral zone is already depressed. To determine these waterside areas, all areas between the lake's average surface of $115.45 \mathrm{~m}$ and $116 \mathrm{~m}$ ground elevation are taken as littoral zones.

Thresholds were applied to estimate three probability levels of inland marshes (Fig. 7.3). These thresholds are derived from reference habitats to deduce high, medium, and low habitat occurrence probabilities. Only land-cover types with a realistic potential for inland marshes were considered for the application of the rule set. CORINE land-cover data were used to mask out land-cover classes with little potential (e.g. urban areas).

\subsubsection{Results}

The results depicted in a habitat probability map (Fig. 7.4) show a transition from Lake Neusiedl in the western part to small probability patterns approximately $10 \mathrm{~km}$ from the main water body.

As expected, areas with the highest probability of occurrence can be found close to the lake. However, because of the low overall variation in altitude the possibility of detecting small depressions is a key feature for salt marshes. Therefore, 


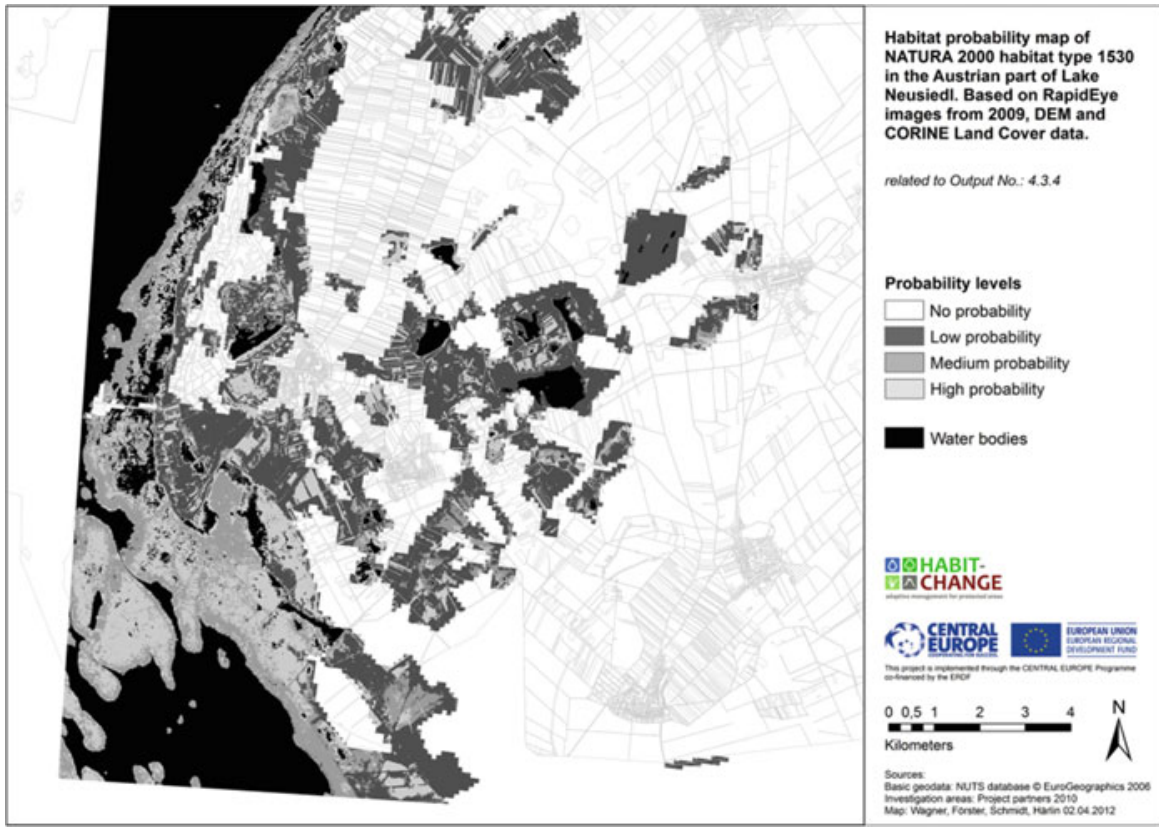

Fig. 7.4 Habitat probability map for the potential occurrence of inland marshes

RapidEye imagery can only be applied in combination with a high resolution DEM. The distribution of the inland marshes shows a realistic pattern which can be found in the area. Due to the difficult accessibility and limited personal resources, insufficient ground-truth data was available to evaluate the results statistically. The derived map could be compared to future probability maps in order to identify changes in the distribution of inland marshes and, thus, to potentially relate the changes to the impacts of climate change and other factors.

\subsection{Case Study Alpine Habitats: Rieserferner-Ahrn, Italy}

\subsubsection{Study Area}

The Nature Park Rieserferner-Ahrn is situated in the eastern Alps, in the northeastern part of the Autonomous Province of Bolzano, Italy (see Fig. 1.1). It encompasses $313 \mathrm{~km}^{2}$ and is characterised by Alpine landscapes and forest zones. Glaciers cover around $5 \%$ of the area and are important water resources. The area is shaped by numerous streams, rivers, waterfalls, and fens. 
Table 7.2 Natura 2000 habitats in the study site

\begin{tabular}{ll}
\hline $\begin{array}{l}\text { Natura } 2000 \text { habitat } \\
\text { code }\end{array}$ & Class definition \\
\hline 3150 & Natural eutrophic lakes with Magnopotamion or Hydrocharition \\
4060 & Alpine and boreal heaths \\
6150 & Siliceous Alpine and boreal grassland \\
6230 & Species-rich Nardus grasslands, on silicious substrates in mountain \\
& areas (and submountain areas in Continental Europe) \\
6520 & Mountain hay meadows \\
7140 & Transition mires and quaking bogs \\
8110 & Siliceous scree of the montane to snow levels (Androsacetalia alpinae \\
& and Galeopsietalia ladani) \\
8220 & Siliceous rocky slopes with chasmophytic vegetation \\
9420 & Alpine Larix decidua and/or Pinus cembra forests \\
\hline
\end{tabular}

The location in the inner Alps south of the Alpine divide renders the climate moderately dry. The study area covers an elevation range from 890 to $3,480 \mathrm{~m}$ above mean sea-level. The vegetation reflects the mountainous character of the nature park. Spruce forests dominate while the timber line is made up of larch and Swiss pine. Increasing in altitude, the vegetation is composed of Alpine meadows and sub-Alpine and Alpine small shrubs and heath. Extreme habitats for plants and animals can be found here. The vegetation above the tree line is very heterogeneous and varies within small areas (Table 7.2).

Agriculture in the study site consists mainly of livestock farming and is characterised by the contrasts of intensification and abandonment. The nature park is managed by representatives of the municipalities, the department of forestry and agriculture, the farmers' association and experts from conservation organisations. The Nature Park is part of the Natura 2000 network of the European Union.

\subsubsection{Climate Change Impact in Alpine Areas}

The Alpine region has seen an exceptionally large increase in temperature of around $+2{ }^{\circ} \mathrm{C}$ between the late nineteenth and early twenty-first century, more than twice the average warming of the northern hemisphere. Regarding precipitation, a slight trend towards an increase in the northern Alpine region and a decrease in the southern region has been recorded (EEA 2009; Auer et al. 2007).

Climate projections for the Autonomous Province of Bolzano show a clear warming trend in all seasons. Until 2050 temperatures are projected to increase between $+1{ }^{\circ} \mathrm{C}$ and $+2{ }^{\circ} \mathrm{C}$ (up to $+2.9{ }^{\circ} \mathrm{C}$ in summer). Future precipitation projections are more heterogeneous and do not show a clear trend. Furthermore, a prolonged growing season, i.e. the period of the year with a daily mean temperature of over $5{ }^{\circ} \mathrm{C}$, is projected. The meteorological water balance, which can be used as an indicator to estimate the requirement of irrigation water, does not show a clear trend in the models. However, local extremes of variations can be expected in future changes of climate (Zebisch et al. 2010). 
The largest pressure on habitats in Alpine areas is land-use. This is true despite land-use activities being limited within the Nature Park due to conservation restrictions. Pressures arise mostly from extensive forestry, agriculture (grasslands with livestock breeding and pasture farming), tourism, and traffic. In this study we investigated the following potential impacts for the study area Rieserferner Ahrn:

- increase in dwarf shrub cover,

- change in tree line,

- new vegetation on rocks and the glacier forefields,

- changes in water regime and intra-annual and inter-annual dynamics,

- changes in phenology and its intra-annual and inter-annual dynamics (Zebisch et al. 2010).

\subsubsection{Data and Methods}

For the study area four RapidEye images (Level 1B) with the acquisition dates 22-07-2009, 29-07-2009, 03-10-2009 and 31-07-2010 were available. The following auxiliary data sets were used:

- a colour aerial orthophoto acquired in 2006 with a spatial resolution of $0.5 \mathrm{~m}$,

- a Digital Elevation Model (DEM) with a spatial resolution of $2.5 \mathrm{~m}$,

- solar radiation layers - from RapidEye images using metadata and DEM,

- texture layers: texture features (Haralick et al. 1973) such as mean, variance, homogeneity, contrast, dissimilarity, entropy, second angular moment and correlation features were generated from the orthophoto,

- detailed habitat thematic map: field mapping 2006 as well as photointerpretation and digitalisation of orthophotos by experts.

Initially the RapidEye images were orthorectified (Toutin 2003) and the pixel values converted to reflectance at top of the atmosphere (TOA). In the latter step only distance to the sun and the geometry of the incoming solar radiation was considered. Next we masked out clouds and shadowed areas in the images using object-based image analysis. Using Definiens eCognition software the images were first segmented and classified into two levels to map clouds and shadows based on object statistics, topological and shape object's features. The mapping results of the two classification levels were then merged. The classification was further improved by modifications of the object's shapes using appropriate features of classified objects. Subsequently, training as well as validation samples of the different vegetation types were derived following a random stratified sampling approach based on thematically homogeneous areas. A minimum of 50 samples were taken from twelve vegetation types present in the study area. The SVM classification 
Table 7.3 Vegetation types classified in the study area and their corresponding habitat types according to the Natura 2000 habitat codes

\begin{tabular}{ll}
\hline Vegetation type & Corresponding habitat type \\
\hline Water bodies & 3150 \\
Alpine heathland & 4060 \\
Alnus (Grünerle) & \\
Pinus mugo & 4060 \\
Natural grassland & 6150 \\
Extensive grassland & 6230 \\
Intensive grassland & 6520 \\
Wetlands & 7410 \\
Pioneer formations & 8110 \\
\hline
\end{tabular}

algorithm was then used to classify vegetation cover. Vegetation classes that can be distinguished in the study area and their corresponding habitat-types are listed in Table 7.3.

In a subsequent step, the classification results were validated using independent reference points. The summarised output is transferred into a confusion matrix for calculating overall accuracy and kappa value. Finally, we reclassified the vegetation classes from the supervised classification into habitat types applying a knowledgebased approach. We defined thresholds for each habitat type including the minimum and maximum percentages of vegetation types, the minimum area and the elevation range. The criteria are taken from the literature, in particular from Ellmauer (2005). Additionally, we included the expertise of biologists at the EURAC Institute of Alpine Environment. We applied a spatial kernel method to calculate the frequency of a class within a given filter window. Both the frequency and the spatial arrangement of class labels within the window are recorded. With this spatial reclassification kernel an adjacency matrix is produced for each pixel and habitat classes are assigned accordingly (Barnsley and Barr 1996). For those pixels where no rule or more than one rule is true the relevant pixel remains undefined. In order to classify such pixels we used a minimum distance classifier. An additional effect is that the reclassification also corrects misclassified data and thus improves the salt and pepper noise of the pixel-based classification (Schmidt 2012).

We assessed the accuracy of the resulting habitat type map (Fig. 7.5) using reference samples carefully selected from the orthophoto and labelled by an independent expert. In order to determine the conservation status of a habitat type we utilised two assessment schemes: that of the German working group of the Federal States and the Federal Government on nature conservation (Länderarbeitsgemeinschaft Naturschutz $=$ LANA) and the Austrian scheme (BMULF). From these schemes we derived disturbance indicators that can be detected on satellite images, the most prominent being shrub encroachment, which can occur in different habitat types, most prominently in grassland types. For each habitat type the schemes give percentages of the area of a habitat which is covered by shrubs and consequently fall in a certain conservation status category. We implemented the LANA definitions of shrub encroachment and the subsequent conservation status in a rule set (result see Fig. 7.6). 


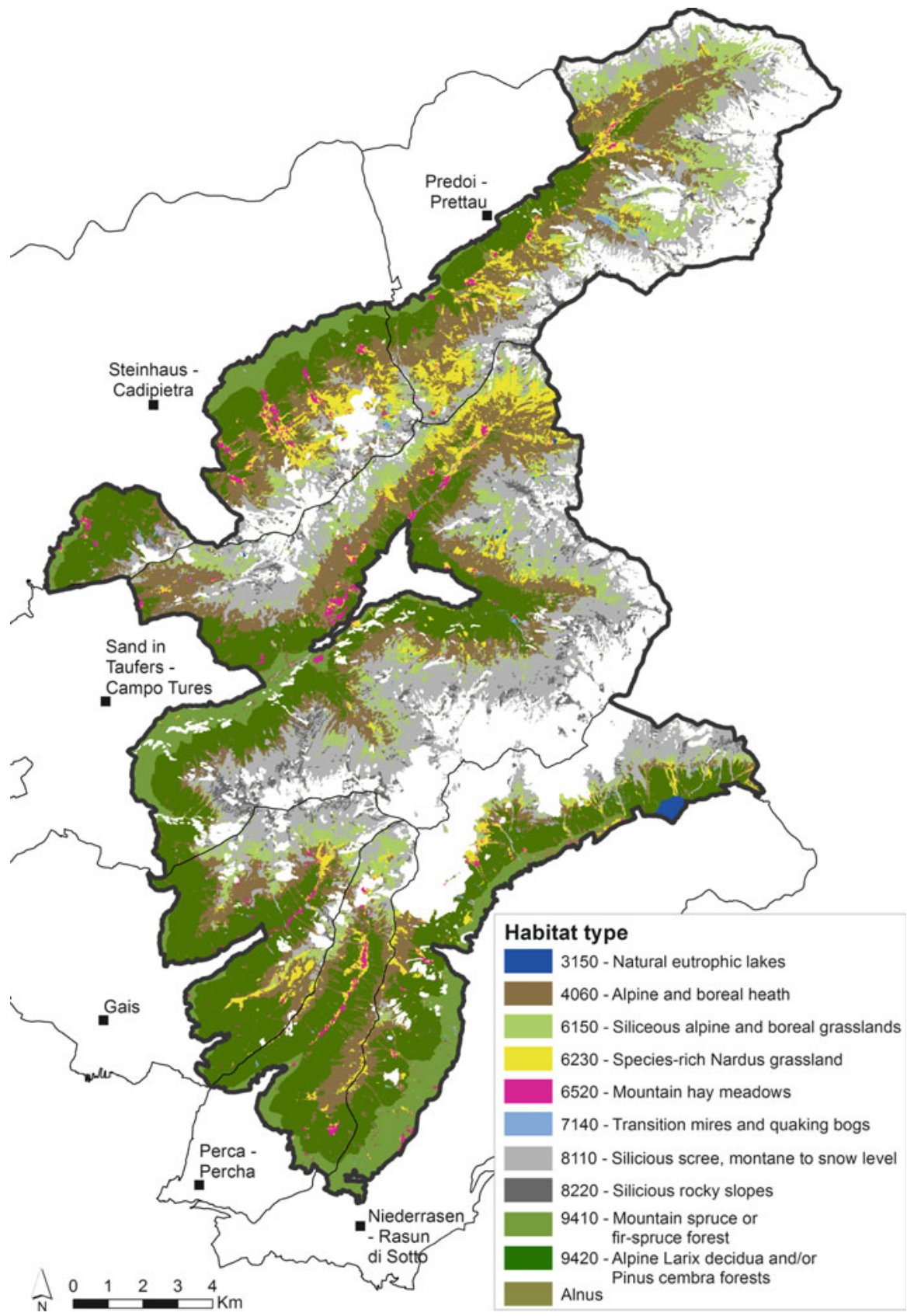

Fig. 7.5 Final habitat map Rieserferner-Ahrn Nature Park according to the Natura 2000 habitat codes 


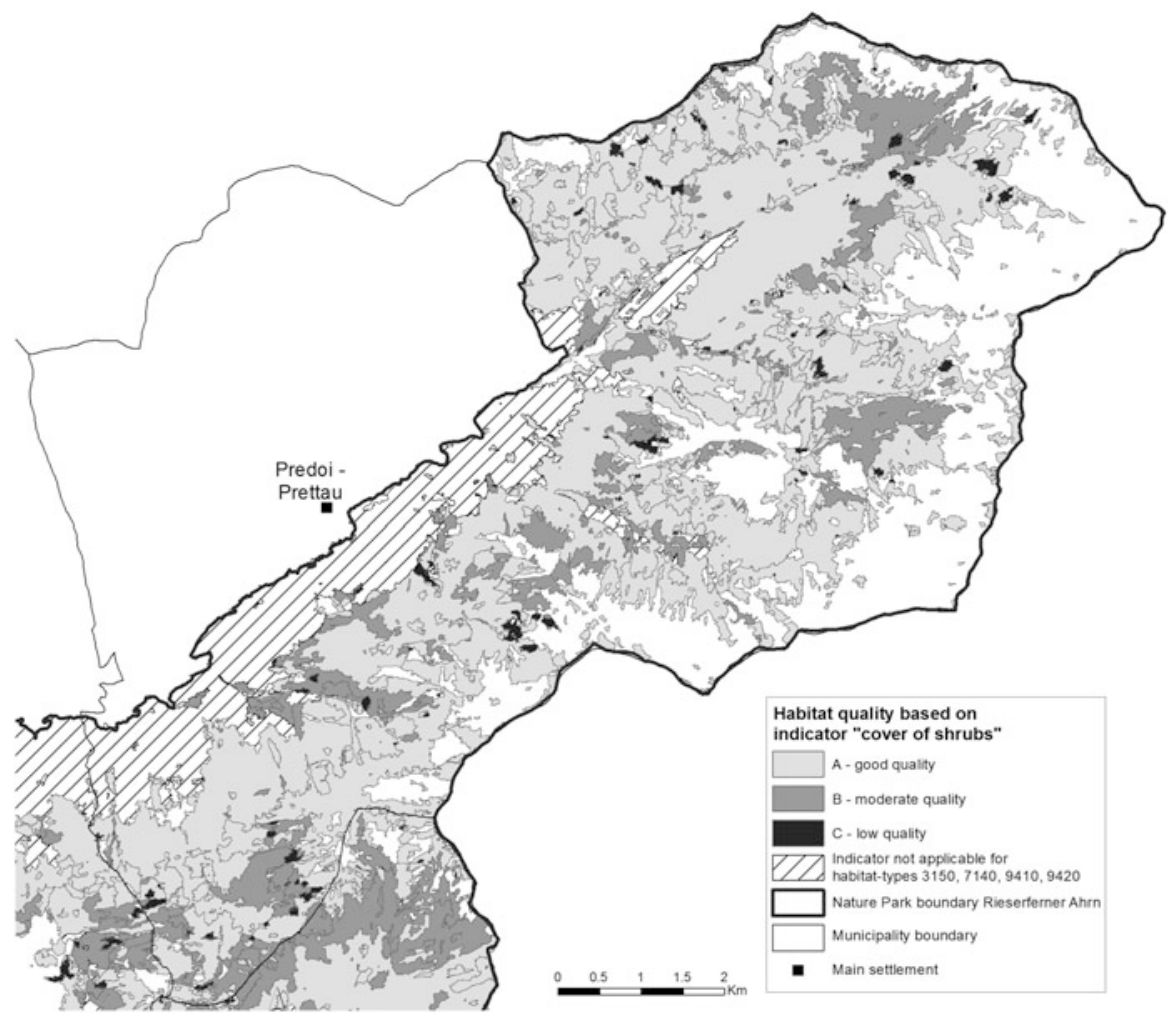

Fig. 7.6 Example for an evaluation of conservation status for the disturbance indicator "shrub encroachment" (for the north-eastern part of the Rieserferner-Ahrn Nature Park)

\subsubsection{Results}

In conclusion, we developed and applied a method to detect habitat types on satellite images that produced results of a quality to be used in regional habitat monitoring (see Fig. 7.5).

The resulting habitat map is $87 \%$ accurate and can be processed further to determine the conservation status of a habitat. Provided that the necessary input data and adequate ground truth data for calibration and validation are available our approach can be replicated in other Alpine areas and for different time periods. The output habitat map could be reproduced regularly for a Natura 2000 site to detect changes and to evaluate the conservation status by means of a disturbance indicator such as shrub encroachment.

\subsubsection{Conclusions}

Multi-temporal high resolution satellite data have high potential for mapping and monitoring habitats in Alpine areas. The shortcomings from the technical side are 
mainly data gaps due to cloud cover, which is a relevant problem particularly in the Alps. The overall accuracy of $87 \%$ is high, taking into account the large number of classes (12). However, while a remote sensing-based classification can hardly reach the accuracy of a field-based survey it can compete with the widely used approach of the photointerpretation of orthophotos. In particular the multi-temporal approach allows classes to be separated based on phenological differences or differences in management (mowing) that cannot be separated using a mono-temporal approach like an orthotophoto. Furthermore, the higher number of spectral bands with a better radiometric resolution and robustness of satellite data compared to orthophotos allow a semi-automatic classification which saves costs and labour. Key factors for a high quality classification result are sufficient samples in terms of amount and quality, which should be verified in the field. Moreover, the combination of automatic classification approaches with expert classification rules, which are based on profound knowledge of the habitats in the region, are required for a successful application of the proposed method. The possibility to also analyse some aspects of the conservation status of habitats adds further value to the approach. Regarding the potential impacts of climate change, the most obvious impact, which is a shift in vegetation zones to higher altitudes (shrubs, treeline, glacier foreland), can be effectively monitored with remote sensing.

\subsection{General Conclusion and Discussion}

In this chapter the possibility of using remote sensing information for monitoring climate-induced impacts on habitats has been demonstrated for three test cases in the Continental, Alpine, and Pannonian biogeographic regions. Moreover, habitats from the land-cover types forest, wetland, and Alpine environment were evaluated to assess the feasibility of supporting the monitoring of climate change impacts.

In those test cases with a validation of the classification results, the accuracy is higher than $80 \%$. Given the complexity of the target classes, this result can be accepted as a basis for the further derivation of the conservation status of classes. Generally, comparison with future image acquisitions for the evaluation of changes is possible. However, these changes might have causes other than pure (and often very gradually occurring) climate change. Variations in market prices of timber or crops may influence usage intensity, as may the subsidy schemes of the European Union or the changing touristic utilisation of an area. It is not possible to distinguish anthropogenic land-use changes from those induced by climate change by means of the methods discussed.

The results were achieved using multi-temporal RapidEye imagery. At least two scenes per year were available for the presented studies. The advantage of utilising several pieces of information from the phenological cycle was stated in all studies, as well as the necessity of working with very high spatial resolution imagery (below $10 \mathrm{~m}$ ). 
However, the compatibility and transferability of such classification results depends on a variety of factors, including:

- comparable and high sampling intensity in space (all necessary classes equally covered) and time (seasonally and/or according to phenological changes of the habitat types),

- comparable sensors and spectral resolution, similar conditions for input imagery (acquisition date/frequency, cloud cover etc.),

- comparable mapping scale or spatial precision: the minimum mapping unit (for vector maps) or the spatial resolution (for raster maps) should be similar,

- comparable mapping accuracy, consisting of thematic accuracy (percentage of correctly classified habitats), and spatial accuracy (habitat delineation errors),

- compatibility of habitat nomenclatures (habitat classification systems).

Summarising the experiences from the HABIT-CHANGE project, a set of key points has to be kept in mind when considering remote sensing techniques for habitat monitoring. In order to fulfil the goal of a focused habitat monitoring integrating remote sensing technique, a clear vision of the outcome (objective) has to be defined. A selection of possible questions is compiled in Table 7.4 for consideration in further studies, for service providers as well as (or together with) users and practitioners of the mapping or monitoring of results.

Table 7.4 List of key issues to be considered for remote sensing-based habitat monitoring (Adapted from Förster et al. 2010). Note that this list is not exhaustive and can be extended (e.g. use of additional data or post-processing)

\begin{tabular}{|c|c|}
\hline \multicolumn{2}{|l|}{ Objective(s) } \\
\hline Which is/are your objective(s)? & $\begin{array}{l}\text { Mapping, indicator assessment, monitoring, } \\
\text { change detection, phenology, others }\end{array}$ \\
\hline \multicolumn{2}{|l|}{ Image data } \\
\hline Which imagery should be acquired? & $\begin{array}{l}\text { Multispectral, imaging spectroscopy, very high } \\
\text { spatial resolution data, LiDAR, others }\end{array}$ \\
\hline What is the image size or path width? & Spatial coverage (geographic extent of the image) \\
\hline $\begin{array}{l}\text { Which spatial resolution is necessary to fulfil } \\
\text { the objective? }\end{array}$ & The ground sampling distance (GSD) of an image \\
\hline $\begin{array}{l}\text { What is the number of bands and wave- } \\
\text { lengths necessary to fulfil the objective? }\end{array}$ & $\begin{array}{l}\text { Specific wavelengths (e.g. short wave infrared, } \\
\text { thermal) }\end{array}$ \\
\hline $\begin{array}{l}\text { Which frequency of image acquisition is } \\
\text { necessary to fulfil the objective? }\end{array}$ & $\begin{array}{l}\text { Mono vs. multi-temporal images (indicate required } \\
\text { acquisition time(s)) }\end{array}$ \\
\hline \multicolumn{2}{|l|}{ Sampling } \\
\hline \multirow[t]{4}{*}{ What is the sampling strategy? } & $\begin{array}{l}\text { Selected (non-random selection of representative } \\
\text { plots of predefined classes) }\end{array}$ \\
\hline & Systematic (e.g. regular grid) \\
\hline & Simple random \\
\hline & Stratified random \\
\hline \multirow{4}{*}{$\begin{array}{l}\text { Which type of ground-truth data } \\
\text { should be collected? }\end{array}$} & Plant species relevés \\
\hline & Vegetation structure relevés \\
\hline & Natura 2000 habitat type \\
\hline & Spectral signature \\
\hline
\end{tabular}


Table 7.4 (continued)

What is the season for acquisition? Which sample size is required?

Remote sensing derived information

Which information should be derived? Which classification approaches are used?

Validation

How should the result be validated?
Month or season
No. of samples, depending e.g. on required mini- mum samples of classification algorithm

Map, change, phenology, others

Pixel-based analysis or object-based analysis

Classification or derivation of gradual vegetation composition

Hard classification or soft (fuzzy) classification

Supervised or unsupervised classification

Spectral or spatial

Based on dependent or independent samples

Automatic validation or visual interpretation

Pixel or polygon based

By confusion matrix or other techniques

Acknowledgements We acknowledge the DLR for the delivery of RapidEye images as part of the RapidEye Science Archive - proposal 439. The TU Berlin thanks Ruth Sonnenschein and Moritz Härlin for their help and fruitful discussions and Steve Kass for working on HABITCHANGE project outputs 4.1.1, 4.3.7, and 4.3.9 that provided part of the basis for the descriptions in this chapter.

Open Access This chapter is distributed under the terms of the Creative Commons Attribution Noncommercial License, which permits any noncommercial use, distribution, and reproduction in any medium, provided the original author(s) and source are credited.

\section{References}

Auer, I., et al. (2007). HISTALP - historical instrumental climatological surface time series of the Greater Alpine Region. International Journal of Climatology, 27(1), 17-46. doi:10.1002/joc. 1377.

Barnsley, M. J., \& Barr, S. L. (1996). Inferring urban land use from satellite sensor images using kernel-based spatial reclassification. Photogrammetric Engineering \& Remote Sensing, 62(8), 949-958.

Berger, M., Moreno, J., Johannessen, J. A., Levelt, P. F., \& Hanssen, R. F. (2012). ESA's sentinel missions in support of Earth system science. Remote Sensing of Environment, 120, 84-90.

Bock, M., Xofis, P., Mitchley, J., Rossner, G., \& Wissen, M. (2005). Object-oriented methods for habitat mapping at multiple scales - case studies from Northern Germany and Wye Downs, UK. Journal for Nature Conservation, 13, 75-89.

Burkhardt, R., Robisch, F., \& Schröder, E. (2004). Umsetzung der FFH-Richtlinie im Wald Gemeinsame bundesweite Empfehlungen der Länderarbeitsgemeinschaft Naturschutz (LANA) und der Forstchefkonferenz (FCK). Natur und Landschaft, 79, 316-323.

Canty, M. J., \& Nielsen, A. A. (2008). Automatic radiometric normalization of multitemporal satellite imagery with the iteratively re-weighted MAD transformation. Remote Sensing of Environment, 112, 1025-1036. 
Duro, D., Coops, N. C., Wulder, M. A., \& Han, T. (2007). Development of a large area biodiversity monitoring system driven by remote sensing. Progress in Physical Geography, $31,235-260$

EEA. (2009). Regional climate change and adaptation - the Alps facing the challenge of changing water resources. Retrieved June 2012, from European Environment Agency, http://www.eea. europa.eu/publications/alps-climate-change-and-adaptation-2009

Ellmauer, T. (2005). Entwicklung Von Kriterien, Indikatoren Und Schwellenwerten Zur Beurteilung Des Erhaltungszustandes Der Natura 2000-Schutzgüter. Band 3: Lebensraumtypen des Anhangs I der Fauna-Flora-Habitat-Richtlinie. Retrieved June 2012, from Bundesministerium f. Land- und Forstwirtschaft, Umwelt und Wasserwirtschaft und der Umweltbundesamt GmbH, http://www.umweltbundesamt.at/fileadmin/site/umweltthemen/ naturschutz/Berichte_GEZ/Band_3_FFH-Lebensraumtypen.pdf

Förster, M., \& Kleinschmit, B. (2008). Object-based classification of QuickBird data using ancillary information for the detection of forest types and NATURA 2000 habitats. In T. Blaschke, S. Lang, \& G. Hay (Eds.), Object-based image analysis (pp. 275-290). Berlin: Springer.

Förster, M., Frick, A., Walentowski, H., \& Kleinschmit, B. (2008). Approaches to utilising Quickbird-data for the monitoring of NATURA 2000 habitats. Community Ecology, 9(2), $155-168$.

Förster, M., Kass, S., Neubert, M., Sienkiwicz, J., Sonnenschein, R., Wagner, I., \& Zebisch, M. (2010). Combined report on list of possible indicators and pressures, guidelines for monitoring and proposal of robust indicators for Alpine Areas, HABIT-CHANGE Output 4.1.1 + 4.3.7. + 4.3.8. Retrieved March 2013, from HABIT-CHANGE, http://www.habitchange.eu/index.php?id=33

Gao, B. (1996). NDWI - a normalized difference water index for remote sensing of vegetation liquid water from space. Remote Sensing of Environment, 58(3), 257-266.

Haralick, R. M., Shanmugam, K., \& Dinstein, I. (1973). Textural features for image classification. IEEE transactions on systems. Man and Cybernetics, 3(6), 620-621.

Karatzoglou, A., Meyer, D., \& Hornik, K. (2005). Support vector machines in R. Retrieved July 20, 2012, form 21. Department of Statistics and Mathematics, WU Vienna University of Economics and Business, http://epub.wu.ac.at/1500/

Lang, S., \& Langanke, T. (2005). Multiscale GIS tools for site management. Journal for Nature Conservation, 13, 185-196.

Lengyel, S., Déri, E., Varga, Z., Horváth, R., Tóthmérész, B., Henry, P. Y., Kobler, A., Kutnar, L., Babij, V., Seliskar, A., Christia, C., Papastergiadou, E., Gruber, B., \& Henle, K. (2008). Habitat monitoring in Europe: A description of current practices. Biodiversity and Conservation, 17, 3327-3339.

Papastergiadou, E. S., Retalis, A., Kalliris, P., \& Georgiadis, T. (2007). Land use changes and associated environmental impacts on the mediterranean shallow lake Stymfalia, Greece. Hydrobiologia, 584, 361-372.

Polastre, J., Szewczyk, R., Mainwaring, A., Culler, D., \& Anderson, J. (2004). Analysis of wireless sensor networks for habitat monitoring. In C. S. Raghavendra, K. M. Sivalingam, \& T. Znati (Eds.), Wireless sensor networks (pp. 399-423). New York: Springer US.

Rocchini, D., Foody, G., Nagendra, H., Ricotta, C., Anand, M., He, K., Amici, V., Kleinschmit, B., Förster, M., Schmidtlein, S., Feilhauer, H., Ghisla, A., Metz, M., \& Neteler, M. (2013). Uncertainty in ecosystem mapping by remote sensing. Computers and Geoscience, 50, $128-135$.

Schmidt, A. (2012). Conversion of a remote sensed vegetation classification to a habitat map Comparing a spatial kernel and an object-based approach (Unpublished diploma thesis).

Schuster, C., Förster, M., \& Kleinschmit, B. (2012). Testing the red edge channel for improving land-use classifications based on high-resolution multi-spectral satellite data. International Journal of Remote Sensing, 33, 5583-5599. 
Soja, G., Züger, J., Knoflacher, M., Kinner, P., \& Soja, A. (2013). Climate impacts on water balance of a shallow steppe lake in Eastern Austria (Lake Neusiedl). Journal of Hydrology, $480,115-124$.

Toutin, T. (2003). Error tracking in IKONOS geometric processing using a 3D parametric model. Photogrammetric Engineering \& Remote Sensing, 69(1), 43-51.

Tucker, C. J. (1979). Red and photographic infrared linear combinations for monitoring vegetation. Remote Sensing of Environment, 8, 127-150.

Turner, W., Spector, S., Gardiner, N., Fladeland, M., Sterling, E., \& Steininger, M. (2003). Remote sensing for biodiversity science and conservation. Trends in Ecology and Evolution, 18, 306-314.

Vehmas, M., Eerikäinen, K., Peuhkurinen, J., Packalén, P., \& Maltamo, M. (2009). Identification of boreal forest stands with high herbaceous plant diversity using airborne laser scanning. Forest Ecology and Management, 257, 46-53.

Wulder, M. A., White, J. C., Masek, J. G., Dwyer, J., \& Roy, D. P. (2011). Continuity of Landsat observations: Short term considerations. Remote Sensing of Environment, 115, 747-751.

Zebisch, M., Kass, S., \& Tasser, E. (2010). Potential pressures + indicators for NATURA 2000 reporting in Alpine Habitats - Nature Park Rieserferner Ahrn, HABIT-CHANGE Output 4.1.4 + 4.1.5. Retrieved July 2012, from HABIT-CHANGE, http://www.habit-change.eu/ index.php?id=33 